\title{
BRIDGING ACADEMICIAN AND COMMUNITY THROUGH KNOWLEDGE TRANSFER PROGRAM (KTP) ON WORKPLACE RISK ASSESSMENT TECHNIQUE- A CASE STUDY
}

\author{
Nur Fazlinna Ab Ghani', Azizan Ramli2,, Kharul Anwar Johari', Mohd Shaiful Zaidi Mat Desa', Norhaslinda Hanapi ${ }^{3}$ \\ ${ }^{1}$ Faculty of Chemical \& Process Engineering Technology, College of Engineering Technology, Universiti Malaysia Pahang, 26300 Gambang, Pahang, \\ Malaysia \\ ${ }^{2}$ Faculty of Industrial Sciences and Technology, College of Computing and Applied Sciences, Universiti Malaysia Pahang, 26300 Gambang, Pahang, \\ Malaysia \\ (ADTEC), KM 9 Jalan Jerantut-Temerloh, 27000, Jerantut, Pahang, Malaysia
}

\begin{abstract}
Since technical education involves equipment and workshop/laboratory activities, safety and health risks due to hazardous situations have become the primary issue and require immediate mitigation measures. The main issue that needs immediate attention here is that most ADTEC (Advanced Technology Training Center) staff lack expertise in workplace risk assessment techniques. Some of them are also unaware of these life-threatening safety and health risks. They are unable to anticipate the long-term impact of their everyday activities on their safety and health. Thus, knowledge of hazard identification and prevention strategies is essential for them to improve their workplace environment. This program has been executed in four stages, which are off-thejob training, walkabout and hands-on activity, oral presentation, and followed by an individual assessment. As for an individual assessment, all participants need to sit the written test and an oral interview. The purpose of an individual assessment is to gauge participant understanding and the effectiveness of the program. The program has been conducted successfully whereby all the 63 participants have undergone the training and passed the assessment (written test and interview). All participants gave very encouraging feedback and believed this program would equip them with knowledge on conducting the risk assessment for all activities in their organization. The authors strongly believe that this initiative and program will ultimately assist ADTEC in reducing the probability of accident occurrence in their organization.
\end{abstract}

ARTICLE HISTORY

Received: 28-4-2021

Revised: 27-5-2021

Accepted: 14-6-2021

\section{KEYWORDS}

Knowledge transfer

Safety and health

Workplace

Risk Assessment

\section{INTRODUCTION}

The country's future does not solely depend on educated personnel but on having a large pool of skilled workers to handle the rapidly changing world of work (Zuraidah, 2008). Thus, the Malaysian government has introduced many technical and vocational development known as Technical and Vocational Education and Training or (TVET) programs in schools, universities, and training centers. According to the Malaysia Education Blueprint (Higher Education), demand for TVET staff will increase by 2020. To fulfill this requirement, the government has raised development expenditure for public TVET institutions, with more than 1,000 TVET in Malaysia to date, of which 506 are public institutions. Advanced Technology Training Center Jerantut (ADTEC-Jerantut) is one of the TVET institutes located in the East Coast region, and this institute offers technical education in the fields of welding, polymer technology, product design, and manufacturing. Technical education and training require the trainers and trainees to be present in the workshop and laboratories for practical and hands-on activities. This condition will expose them to a wide range of potential hazards, notably if hazard mitigation is lacking or under control. The presence of hazards without adequate preventive measures will place workers at risk of injury (Lay et al., 2017).

As a technical education institution, all staff and students deal with equipment, machinery, and workshop/laboratory activities other than office activities. There is a lot of safety and health risk relevant to the work being undertaken in the workshop. It is because workshop and laboratory activities involve much physical movement and manual handling. Other than that, staff and students may expose to particular safety and health risks such as dust, noise, electrical/mechanical (using of machines), and hazardous chemicals, to name a few. The main problem that needs to addressed immediately is that most ADTEC staff lacks experience with workplace risk assessment techniques. Some of them are even unaware of these life-threatening safety and health risks. They fail to anticipate the long-term consequences of their daily activities in workshops and laboratories on their safety and health. Moreover, this newly-established institute has inadequate 
information regarding occupational safety and health hazards due to little exposure to such information and lack of experience.

A planned risk management strategy in a technical education institution is essential to avoid accidents and workrelated health issues for both staff and students and create a culture of sensible risk management linked to a curriculum where students can improve their ability to evaluate and manage risk. Risk is part of daily life, but incidents do not need to occur, so that ADTEC-Jerantut needs to ensure staff, students, and visitors are secured; it is essential to ensure that students are aware of workplace risk assessment for the next generation in the industry. In this case, 'teaching safely' and 'teaching safety' will go hand in hand, especially for technical education institutions. A risk assessment is a close review of anything that could cause people suffering from injuries or ill health when at work. It is a tool that can help both staff and students in to identify and control risks in a systematic and prioritized way.

The Knowledge Transfer Program (KTP) would enhance and improve ADTEC's workplace environment, particularly their workshop and laboratories, by sharing and transferring knowledge and university expertise. This initiative and program will ultimately reduce the probability of accident occurrence. Furthermore, while the focus of this program is on providing ADTEC's employees with workplace risk assessment skills and techniques, we will also assist them in establishing an internal reporting and monitoring system. This system will enable their employees and students to participate in workplace risk assessments and share the information internally.

Therefore, this study aims to conduct training and coaching to identify occupational safety and health hazards related to workshop and laboratory activities. Besides, to enhance the knowledge of workplace risk assessment amongst Adtect's staffs and upskill their hazard identification technique. It also improves workplace condition and minimizes to as low as reasonably possible any potential safety and health hazards at Adtec's workshop and laboratory.

\section{LITERATURE REVIEW}

Hazard is defined as any source of possible damage, harm or adverse health effects to someone or something where the danger is a possibility or probability that a person will be harmed or have an adverse health effect if exposed to a hazard (Canadian Center for Occupational Health \& Safety). Similarly, Health \& Safety Executive (UK) defined hazard as something that could cause harm where there is a high or low risk that anyone will be harmed by these and other hazards, along with an indication of how severe the harm could be. Therefore, the efforts to either eliminate or minimize those potential hazards should be given a priority as part of organization responsibility to avoid an accident. The process to identify the hazards and introduce the intervention strategy is important in order to minimize the accident probability at workplace. Workplace Risk Assessment (WRA) is one of the risk assessment technique which is widely used for this purpose. Risk assessment is the process of determining possible hazards (hazard identification), evaluating and determining the risks associated with those hazards (risk assessment), and identifying appropriate ways to remove or managing that hazards (risk control). For instance, Ministry of Manpower, Singapore defined risk assessment as a process for defining, evaluating and managing risks at the workplace. The risk assessment is necessary to develop the prevention program for workplace injury and diseases (Fox et al., 2018).

There was a study done in Korea by Kim and Jung (2016) which have revealed that improving the study of workplaces and health education programs amongst employees is important in order to enhance workplace health prevention programs. Through this KTP-PSH program which emphasize on WRA and risk control, all participants (ADTEC's staffs) will be equipped with worksite analysis technique. This skill will assist their organization to conduct in-depth analysis of the potential hazards and propose for further improvement. The purpose of this program is not only to train and coach ADTEC staffs about WRA technique but it is also one of the effective drivers to assist organization in inculcating safety culture. This is in line with the argument highlighted by Yangho Kim et al. (2016). They contended that while the implementation of health and safety management systems has significantly reduced the occurrence of occupational injuries and diseases, these systems are not successful when accompanied by a positive workplace safety culture. Terwoert et al. (2016) also argued that in the context of inter-company cooperation, risk management of their companies can be enhanced with the help of active training and coaching, especially chemical risk management.

In addition to trainings, employee involvement in safety and health programs is also essential. In other words, employee empowerment will complement and enhance organizational activities. For example, findings from the study done by Lenhardt and Beck (2016) recommend that reinforcement of staff participation structures at company level will be conductive to the implementation of WRA. WRA will help organization recognize possible safety and health hazards which may exist at their workplace. Before that, knowledge about safety and health hazards ought to be disseminated to them, so as the techniques and strategies for hazards preventive and control measures. Without WRA, organization will not be able to identify appropriate preventive measures that might finally expose them to an accident.

The risk assessment plays a role as a safety review tool in the workplace to assess whether sufficient or more action has been taken to prevent potential harms ( Gul \& Ak, 2018). The workplace risk assessment process requires involvement from all, from the high level of the management to the lower level of employees. If the organization fails to understand the concept and needs of conducting risk assessment by identifying all potentials hazards from comprehensive perspective, an accident is potentially to occur at any time. Pertaining to this point, Oakman et al. (2018) have given an example of risk assessment of musculoskeletal disorders (MSDs) whereby the factor related to psychosocial hazards get less attention. Thus, the risk assessment process also needs to consider psychosocial hazards in addition to widely known hazards such as physical, chemical and biological, to name a few. 
Poor working posture is a common problem in many field organizations that can lead to various problems of the human body, especially MSDs and physiological stress (Basahel, 2015). MSDs are a major issue in employment health for workers in developed and developing countries, including Malaysia (Maakip et al., 2016). MSDs such as including lower back pain, arm and neck muscle or tendon sprains and joint injuries, to name a few, have a major effect on staff workability (Kalkis, 2015). This will also effect employee productivity and in the long run, organization tend to become under productive and finally result in economic loss. Oakman et al. (2018) contended that in order to minimize the risk of MSD and mental health problems, current strategies should be tackled all possible psychosocial hazards and focus more on removing or reducing source risk. Beside the issue of MSD, noise pollution is also a major concern especially when we deal with huge equipment and machineries. It is known than individual noise levels were strongly influenced by personal behaviors, but also seemed to rely on environmental noise levels (Kraus et al., 2015). Workshop activities at technical training institute typically involve movement of the goods and equipment. Activities using machine and all kinds of handy tools are amongst the common phenomenon that can be seen. Trainer (technical staff) and students are always expose to hazardous condition and without any preventive measure, serious injury can't be avoided, whether due to short term exposure or in the long run.

The presence of metal dust such as stainless steel's welding activities of stainless steel was also able to create fumes that include carcinogenic and neurotoxic metals with concentrations reaching Limit Values (LV) (Stanislawska et al., 2017). Thus, because of various complexity, there is a need for organization to plan for precautionary measures. An ability to anticipate the consequences and plan for prevention will help them to take necessary precaution in advance. Furthermore, health hazards also relate to hazardous chemicals being used in workshop and laboratory especially carcinogenic chemicals. Thus, workplace risk assessment is an important tool to assess occupational safety and health vulnerability and prevent workplace injury.

\section{METHODOLOGY}

\section{Participants and Duration}

Sixty-three Adtec staff have participated in this training which is technical and administrative staffs. All participants were divided into two batches; the first batch was conducted in 2019, while the second batch was conducted in 2020. Each batch was separated into two groups which each group consist of 16 to 17 participants. The duration of this training for each group was conducted for two days.

\section{Workplace Risk Assessment Program Process}

Through this KTP-PSH program, ADTEC's workplace environment, particularly its workshop and laboratories, will be enhanced and improved by sharing and transferring knowledge and university expertise. This initiative and program would ultimately reduce the probability of accident occurrence. Furthermore, this program was designed to provide ADTEC employees with workplace risk assessment skills and techniques and assist them in establishing an internal reporting and monitoring system. This program allowed their employees and students to participate in workplace risk assessments and share the information internally. The knowledge transfer had been delivered through blended learning via classroom theory and practical training.

This section explains the process flow of this programme. Figure 1 shows the flow of Workplace Risk Assessment Program. The process started with safety review to identify the risk in daily operations at current workplace condition (ADTEC Jerantut). Then, the academia (UMP) prepared the module to increase the safety of workplace. The participants just involved in pre-training, training, post training and assessment only. The details explain in subsection below.

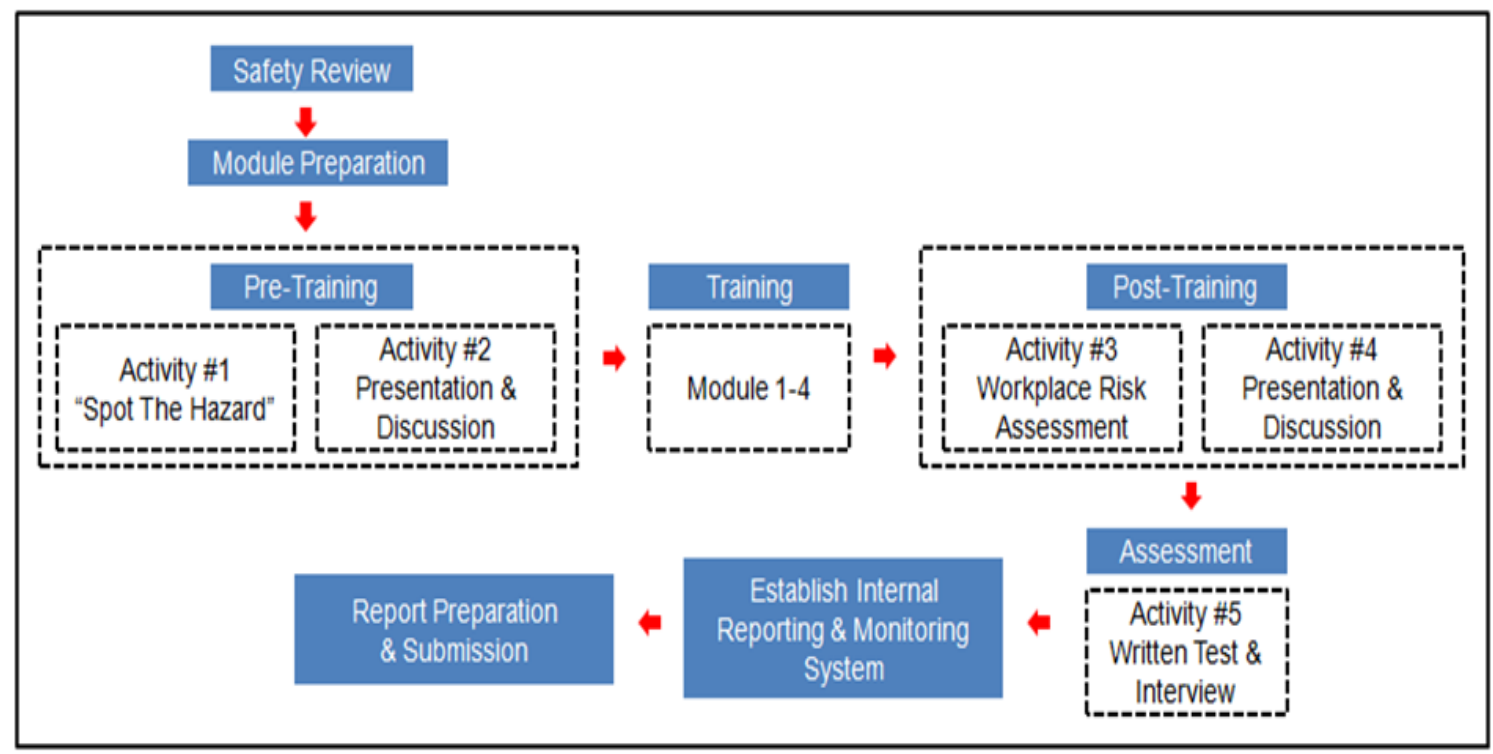

Figure 1. Workplace Risk Assessment Program Process Flow 


\section{Pre-Training}

In Pre-training consists two activities which is for the first activity which was "Spot the Hazard", participants had identified hazard for specific workplace or scenario given in the classroom or at site. The second activity they will sit down, discuss and present their finding by group. Each group had the opportunity to discuss their finding and finalized credible hazards.

\section{Training}

There were four Modules in total for the training. Module 1 was about Introduction to Workplace Safety and Health Hazards. Participant had been exposed to the overview of occupational safety and health scenario in Malaysia. They also exposed to the hazards that were commonly found and previous accidents for lesson learnt. This module had explained on theories about accident causation and hazards classification.

Module 2 focused on legislation framework in Malaysia, starting with the evolution which include history and development of occupational safety and health. Participants had been introduced to Factories and Machineries Act 1967 and Occupational Safety \& Health Act 1994. Furthermore, this module had explained on having a safe workplace in compliance to the Malaysian Government Standard. By having common understanding that everybody had their own role to play, staffs and students can make a responsible and informed contribution to the safety and health effort.

Module 3 explained on type of workplace safety \& health hazards. Participants had been exposed to the fundamentals of toxicology, physical hazards, mechanical hazards, biological hazards, physiological hazards and chemical hazards. Hazard identification was a step in determining whether a situation, item, or thing had the potential to cause harm. Participants learned how to identify potential health and safety hazards in the workplace by examining conditions or practices.

In Module 4, participants were exposed to conducting hazard identification, risk assessment and risk control according to the guideline produced by the Department of Occupational Safety and Health (DOSH). Hazard Identification, Risk Assessment, and Risk Control (HIRARC) were the starting points for identifying potential harm or danger and analyzing its magnitude and risk to implement appropriate controls. Hazard identification was the recognizing of things that may cause injury or harm to a person. Risk assessment was looking at the possibility of injury or harm occur to a person if exposed to a hazard. Risk control refers to implementing measures that eliminate or reduce the risk of a person being exposed to a hazard. As a result, HIRARC ensures compliance with legal as well as management system requirements. The Modules was simplified in Table 1.

Table 1. The list of Modules Training (off-the-job training)

\begin{tabular}{|c|c|c|}
\hline Module & Title & Description \\
\hline 1 & $\begin{array}{l}\text { Introduction to Workplace Safety and Health } \\
\text { Hazards }\end{array}$ & $\begin{array}{l}\text { - An overview of occupational safety and } \\
\text { health in Malaysia } \\
\text { - } \quad \text { Introduction to workplace risk assessment }\end{array}$ \\
\hline 2 & Occupational Safety and Health Legislation & $\begin{array}{l}\text { - } \quad \text { Factories and Machineries Act } 1967 \\
\text { - } \quad \text { Occupational Safety \& Health Act } 1994\end{array}$ \\
\hline 3 & Type of workplace safety \& health hazards & 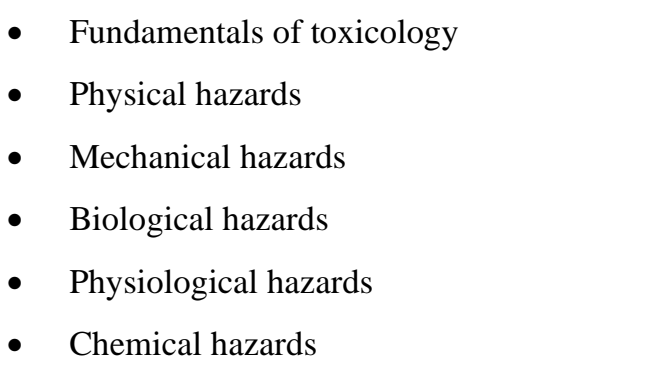 \\
\hline 4 & $\begin{array}{l}\text { Hazard Identification, Risk Assessment \& } \\
\text { Risk Controls }\end{array}$ & $\begin{array}{l}\text { - } \quad \text { Hazard identification technique } \\
\text { - "Workplace-watching" } \\
\text { - Assessment \& risk matrix }\end{array}$ \\
\hline 5 & Workplace Risk Assessment Reporting & - Do the report about the risk assessment \\
\hline
\end{tabular}




\section{Post-Training}

After attending the training, participants were doing the third activity which was Workplace Risk Assessment. They will select work activity from their daily tasks and do risk assessment by using HIRARC. Participants also had been given the opportunity to observe the demonstration of selected work activity. Upon completing HIRARC, participants were able to identify hazard in workplace, assess the risk of identified hazards, provide control measure to mitigate hazards to ALARP (As Low as Reasonably Practicable) and come out with recovery measures. Again, they will sit down, discuss and present their finding by group. Each group will have the opportunity to discuss on the work activity process flow, identified hazards, risk rating given and the propose control measures.

\section{Assessment}

In order to test participants understanding and capability to conduct their own Workplace Risk Assessment, a session of written test and interview session had done for ADTEC staffs. They were evaluated based on several criteria such as appearance, greeting, communication, body language, posture and eye contact, politeness, general attitude, responses to questions, candidate integrity and overall demonstration of interview skills. Interview questions were attached in appendix A. For the written test, the participants were answered all the part of the question, which is Part A (objective question), Part B (true or false question) and Part C (subjective question) and graded by the project leader.

\section{FINDINGS AND DISCUSSIONS}

\section{Pre-Training}

\section{Activity 1: "Spot the Hazard"}

This activity started by looking at what participants from different backgrounds already knew about hazards. Two workstations were selected (Figure 2) as case studies based on participants background so that participants can appreciate the activity. Participants went to selected workstations and try to identify any hazard available at the area. From their observation, they will list down potential hazards. All participant shown improvement in identifying hazard in second activity after learning from the first workstation.

The purpose for this study was to sharing knowledge on workplace risk assessment technique to ADTEC staffs. This program raised awareness of the relationship between safety and health and the prevention of workplace occupational risks. From this program, the participants had recognized the variety of occupational hazards at the workplace such as physical hazards, mechanical hazards, biological hazards, physiological hazards, and chemical hazards. According to Hussain et al. (2018), the workplace training was efficient in improving worker awareness of the hazards.

The results from the knowledge transform program indicated that the staffs of ADTEC Jerantut felt that they themselves were primarily responsible for ensuring that they had the skills to perform their tasks safely. The provisions of the work environment management system were not very well known to the staffs. After this program, the staff know how to conduct risk analyses and prevent risks at the workplace.

Early recognition of hazard in materials, substances or products is a fundamental prerequisite for correct and safe handling. The values of awareness, respect and risk anticipation have risen in the ADTEC Jerantut community. The process of 'spot the hazards' is promoted by creative thinking as well as leverage team experience.

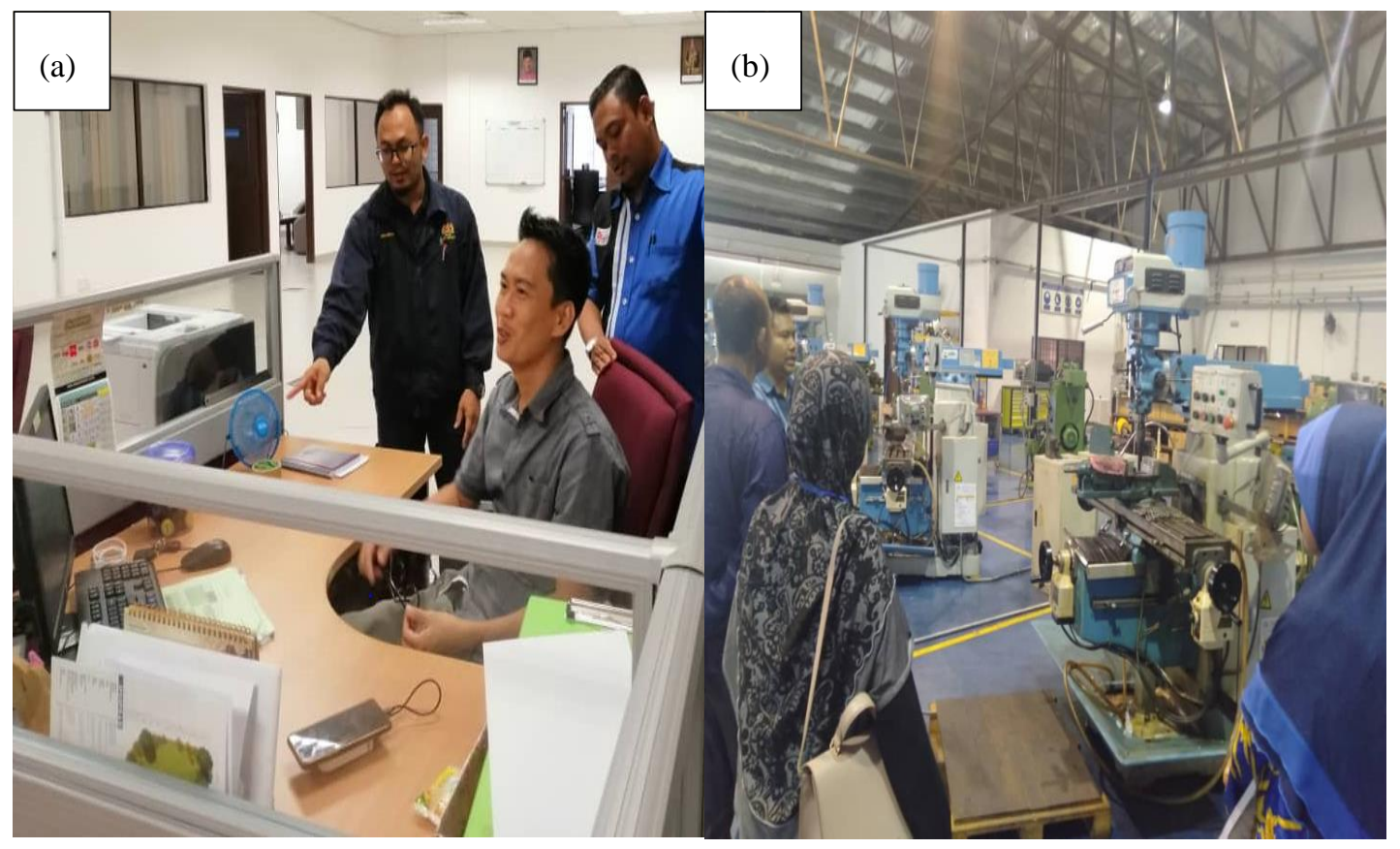

Figure 2. Spot the hazards at (a) Office Workstation and (b) Workshop Workstation 


\section{Activity 2: Presentation and Discussion}

During this session, the participants learned about the hazard identification and the classification. Participants listed down all findings and present it in groups (Figure 3). From the discussion conducted during this session, participant shown significant understanding on the hazards associated with the works station. It also helped highlighting the different perceptions on hazard that exist between them.

Participants described these problem-solving skills as the ability to recognize potential safety issues or hazards, an understanding of how those issues and hazards can and should be addressed by employers and employees, and then having the communication skills, strategic planning skills, and confidence to raise concerns effectively with their supervisors, or to identify resources and strategies to protect themselves even in less-than-ideal work environments.

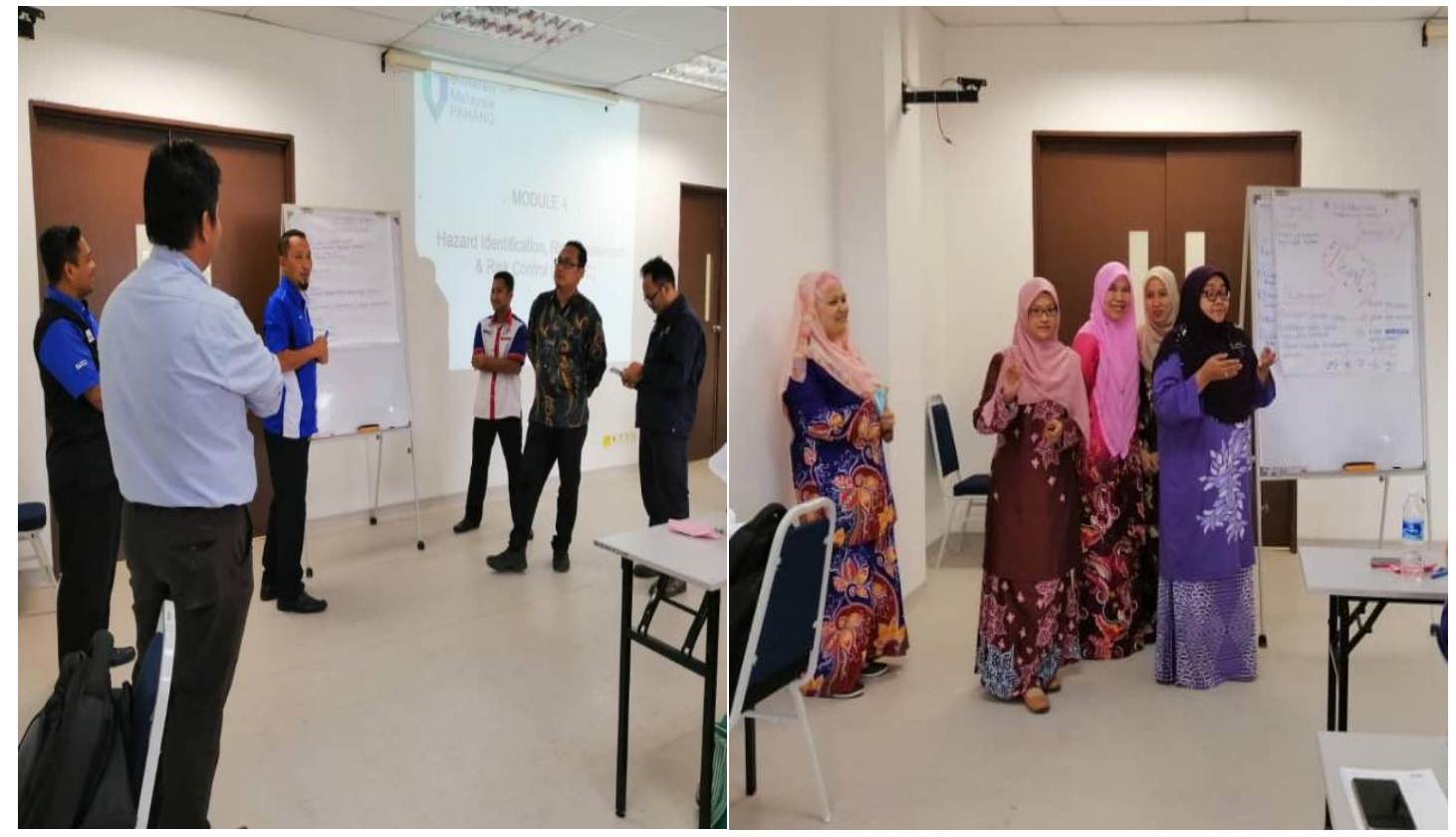

Figure 3. Group presentation for pre-training session

\section{Training}

Employees gain the skills and knowledge they need to perform their jobs safely and without putting their health at risk through information, instruction, and training. It enables them to follow health and safety procedures, use risk controls set in place for their protection, and have an appreciation of the nature of the hazard; the risks associated with their use; and the reason why risk controls are used.

There are four modules that will be taught to the participants. Starting with the introduction, followed by related legislation, and Hazard Identification, Risk Assessment and Risk Control (HIRARC) (Figure 4). The participants must be trained in the risk assessment process and be familiar with the regulations associated with the hazard, have a practical understanding of the work hazards, and consult with the Health and Safety Representative.

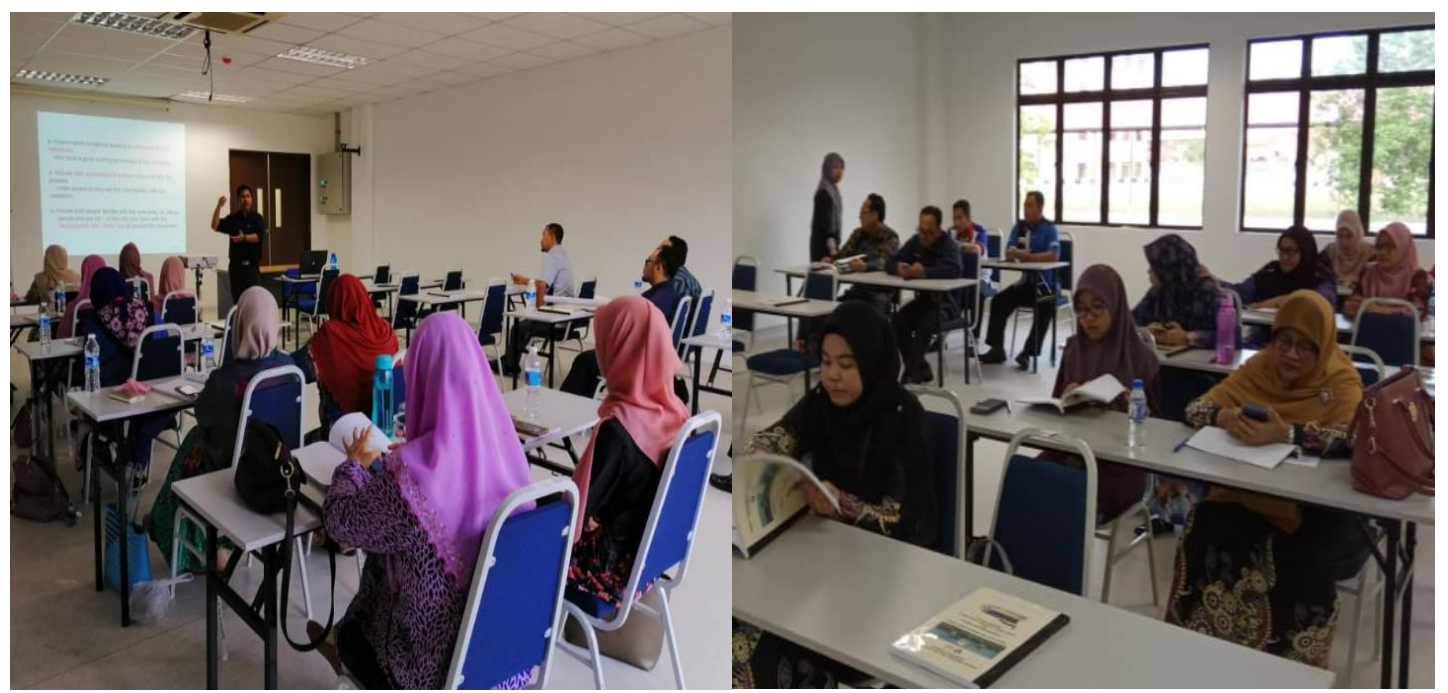

Figure 4. The training session in the class 


\section{Post-Training}

Activity 3: Workplace Risk Assessment

Participant will be exposed to two type works at different workstations. Again, the workstations were selected based on participants' background so that participants can appreciate the activity. Participants went to selected workstations and watch a demonstration on the activity. From their observation, they will list down all the work activity. For example, the instructor demonstrated on how to operate conventional milling machine as shown in Figure 5. Participants had listed down all work activity based on the explanation earlier.

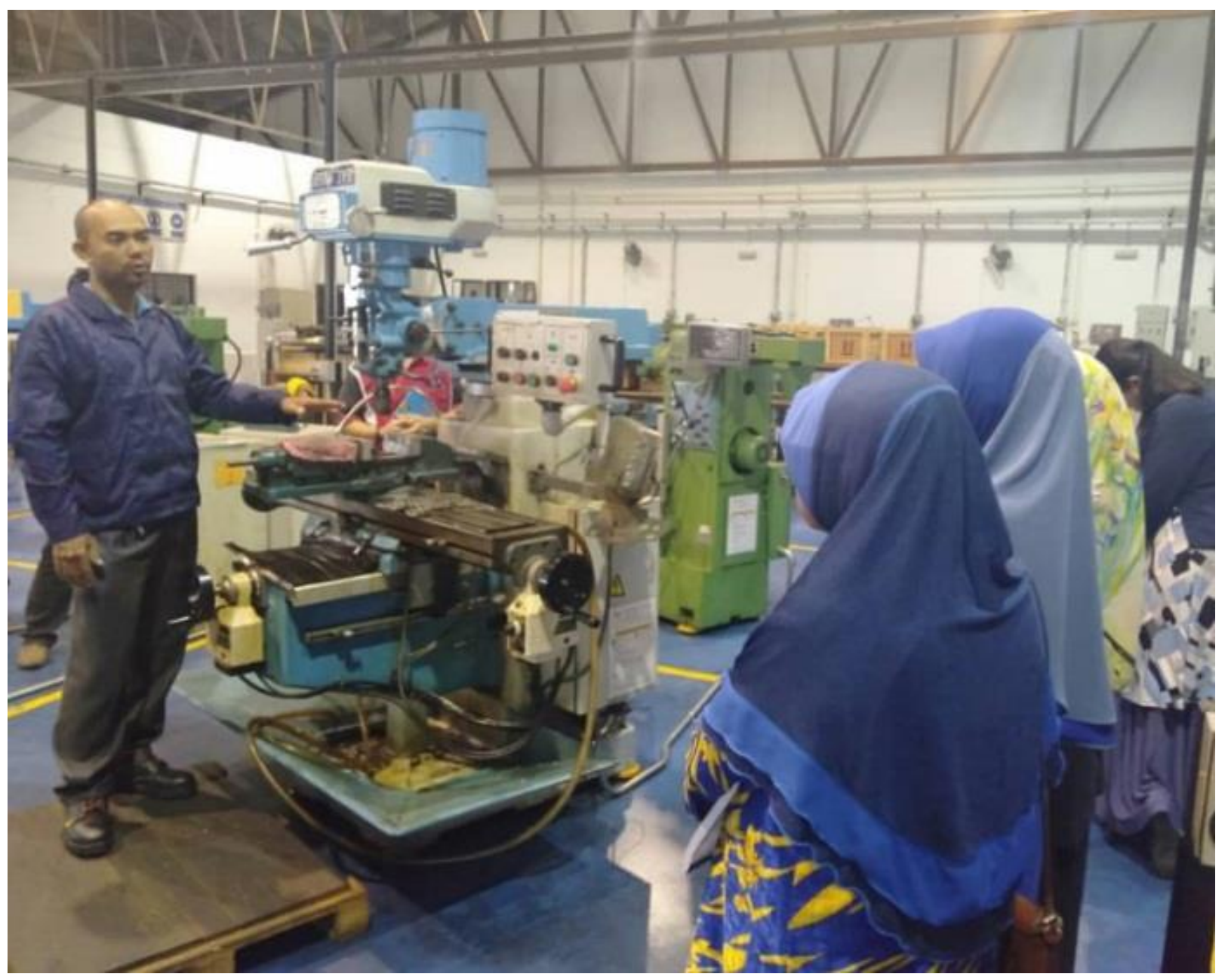

Figure 5. Conventional milling machine demonstration by instructors

\section{Activity 4: Presentation and Discussion}

From work activity that has been observed earlier, participants will develop Hazard Identification, Risk Assessment and Risk Control (HIRARC). Each group presented and defended their judgment (Figure 6). Based on the discussion conducted, participants had better view on the overall risk assessment done; work activity process flow, identified hazards, risk rating given and the propose control measures. There were two work activities observed by participants. All participant shown improvement in conducting HIRARC in second activity after learning from the first work activity. From the discussion conducted during this session, participant shown significant understanding on conducting HIRARC. 


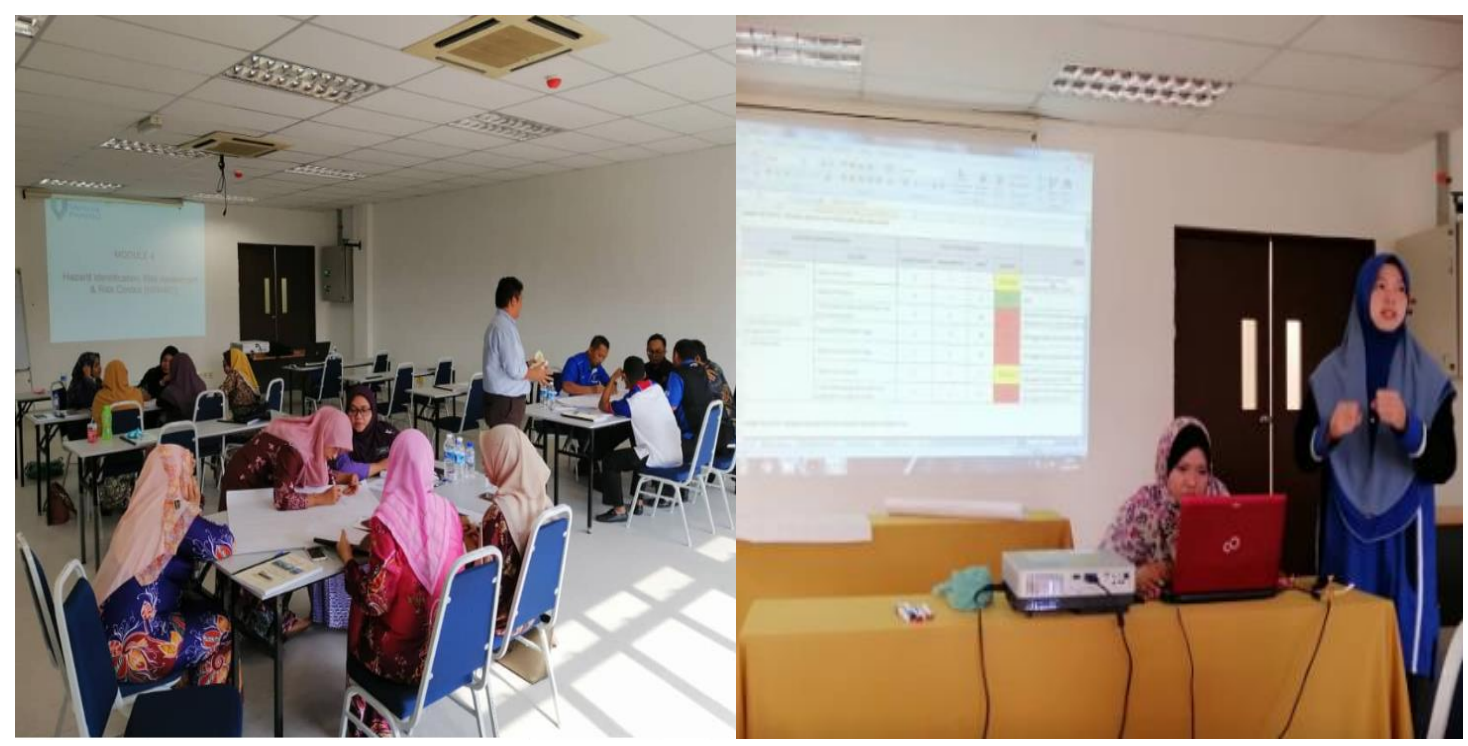

Figure 6. Participants preparing and presenting HIRARC

\section{Activity 5: Written Test and Interview}

To test participants understanding and participants capability to conduct their own Workplace Risk Assessment, a session of written test and interview session (Figure 7) has been arranged for each batch. The participants from all batch had attended the written test and interview session. The total participants attended the written test were 63 participants, while the interview session only 60 participants attended, and another 3 persons absent because they have outstation to HQ throughout the week for syllabus development. Table 2 and Table 3 shows the marks for written test and interview session.

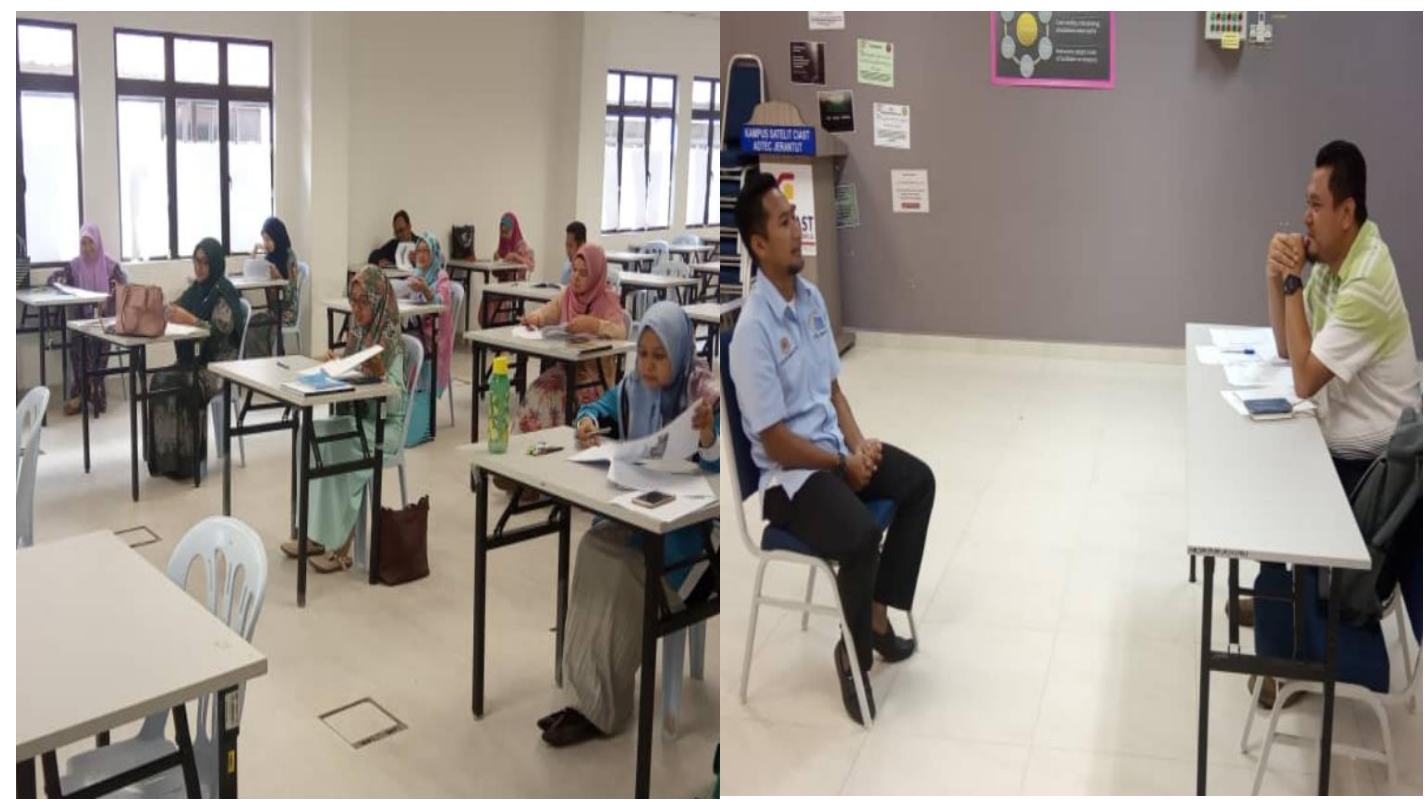

Figure 7. A written Test session and an interview session

The marks for writing test (Table 2) $38.1 \%$ of participants had the marks above $90 \%$. Meanwhile, $50.8 \%$ of participat got range marks between 80 to 89 mark and another $11.1 \%$ had the marks below the $90 \%$. From Table 3, 80\% participants get marks above $90 \%$ for interview results, while the others had marks below $90 \%$ which are $18.3 \%(80-89 \%)$ and $1.7 \%$ (below $80 \%$ ). Based on the results of the study, it was found that most of the respondents got higher marks for the writing tests and interview sessions of their knowledge after training on risk assessment techniques in the workplace was given. The types of control proposed in this study in order to eliminate the hazards were administrative control and personal protective equipment (PPE) control. PPE control (application of mask and glove) were also advised due to the health impact of the chemical hazards. 
Table 2. Written Test results for participants

\begin{tabular}{lcc}
\hline Range marks & Number of persons & Percentage (\%) \\
\hline 90 and above & 24 & 38.1 \\
$80-89$ & 32 & 50.8 \\
Below 80 & 7 & 11.1 \\
& & \\
\hline Total & $\mathbf{6 3}$ & $\mathbf{1 0 0 . 0}$ \\
\hline
\end{tabular}

Table 3. Interview results for the participants

\begin{tabular}{lcc}
\hline \multicolumn{1}{c}{ Range marks } & Number of persons & Percentage (\%) \\
\hline 90 and above & 48 & 80 \\
$80-89$ & 11 & 18.3 \\
Below 80 & 1 & 1.7 \\
& & \\
\hline Total & $\mathbf{6 0}$ & $\mathbf{1 0 0 . 0}$ \\
\hline
\end{tabular}

\section{CONCLUSION}

Participants shown massive improvement from the beginning of the program until its completion. Participants were able to conduct risk assessments for all activities in their organization and recommend the best solutions to mitigate any unacceptable risks. Other than that, an application has been developed for internal usage to report any hazard found in ADTEC-Jerantut together with the classification. Therefore, all active staffs consist of technical and administrative staffs can play their role. In the future, ADTEC-Jerantut management can develop long term approach in order to manage risk associated with technical education institution and build a culture of sensible risk management.

\section{ACKNOWLEDGEMENT}

We would like to thank Ministry of Education Malaysia and Universiti Malaysia Pahang for the financial assistance. This project has been financially supported through Knowledge Transfer Program Grant; LL(R4)-MHC/6 (UMP-19) [RDU191002].

\section{REFERENCES}

Basahel, A. M. (2015). Investigation of Work-related Musculoskeletal Disorders (MSDs) in Warehouse Workers in Saudi Arabia. Procedia Manufacturing, 3, 4643-4649.

Fox, M. A., Spicer, K., Chosewood, L. C., Susi, P., Johns, D. O., \& Dotson, G. S. (2018). Implications of applying cumulative risk assessment to the workplace. Environment International, 115, 230-238.

Gul, M., \& Ak, M. F. (2018). A comparative outline for quantifying risk ratings in occupational health and safety risk assessment. Journal of Cleaner Production, 196, 653-664.

Hussain, R., Pedro, A., Lee, D. Y., Pham, H. C., \& Park, C. S. (2018). Impact of safety training and interventions on training-transfer: targeting migrant construction workers. International Journal of Occupational Safety and Ergonomics, 26(2), $272-284$.

Kalkis, H. (2015). Economic Analytical Methods for Work-related MSD Cost Prediction. Procedia Manufacturing, 3, 4181-4188.

Kim, Yangho, Park, J., \& Park, M. (2016). Creating a culture of prevention in occupational safety and health practice. Safety and Health at Work, 7(2), 89-96.

Kim, Yeon-ha, \& Jung, M. (2016). Analysis of Workplace Health Education Performed by Health Managers in Korea. Asian Nursing Research, 10(3), 246-253.

Kraus, U., Breitner, S., Hampel, R., Wolf, K., Cyrys, J., Geruschkat, U., Gu, J., Radon, K., Peters, A., \& Schneider, A. (2015). Individual daytime noise exposure in different microenvironments. Environmental Research, 140, 479-487.

Lay, A. M., Saunders, R., Lifshen, M., Breslin, F. C., Lamontagne, A. D., Tompa, E., \& Smith, P. M. (2017). The relationship between occupational health and safety vulnerability and workplace injury. Safety Science, 94, 85-93.

Lenhardt, U., \& Beck, D. (2016). Prevalence and quality of workplace risk assessments - Findings from a representative company 
survey in Germany. Safety Science, 86, 48-56.

Maakip, I., Keegel, T., \& Oakman, J. (2016). Prevalence and predictors for musculoskeletal discomfort in Malaysian office workers: Investigating explanatory factors for a developing country. Applied Ergonomics, 53, 252-257.

Oakman, J., Macdonald, W., Bartram, T., Keegel, T., \& Kinsman, N. (2018). Workplace risk management practices to prevent musculoskeletal and mental health disorders: What are the gaps ? Safety Science, 101(December 2016), 220-230.

Stanislawska, M., Halatek, T., Cieslak, M., Kaminska, I., Kuras, R., Janasik, B., \& Wasowicz, W. (2017). Coarse, fine and ultrafine particles arising during welding - Analysis of occupational exposure. Microchemical Journal, 135, 1-9.

Terwoert, J., Verbist, K., \& Heussen, H. (2016). An Intervention Study on the Implementation of Control Banding in Controlling Exposure to Hazardous Chemicals in Small and Medium-sized Enterprises. Safety and Health at Work, 7(3), $185-193$.

Zuraidah, M. Z. (2008). TVET in Malaysia. http://dspace.unimap.edu.my/xmlui/bitstream/handle/123456789/7186/TVET in Malaysia.pdf?sequence $=1 \&$ isAllowed=y

\section{APPENDIX A}

\section{Knowledge Transfer Program (KTP) interview questions}

1. Tell us a little about your career background.

2. How long have you been working at Adtec Jerantut? Describe the roles and tasks throughout this institution.

3. Do you have experience as a member of any committee related to occupational safety and health?

4. On a scale of $1-10$, do you feel your current job is highly vulnerable to accident and health risks at work? Leave a comment.

5. Give some examples of accident and health risks that may occur in your workplace?

6. State the actions you can take to reduce or avoid the risk of the accident.

7. Based on your personal assessment after taking this course, please comment:

a. Knowledge gained and

b. How can it be used to improve occupational safety and health aspects at Adtec Jerantut. 


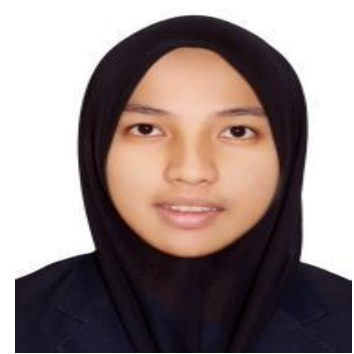

is a Master student at Faculty of Chemical and Process Engineering Technology, College of Engineering Technology, Universiti Malaysia Pahang.

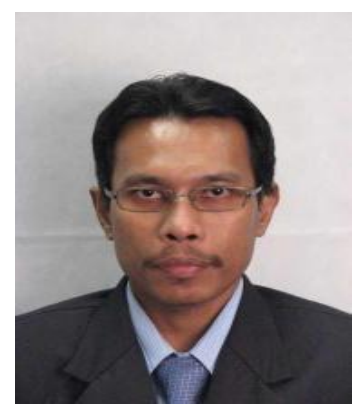

Azizan Ramli is a senior lecturer at Faculty of Industrial Sciences \& Technology, College of Computing \& Applied Sciences, Universiti Malaysia Pahang, Malaysia where he teaches process safety, occupational safety, health \& environment and process engineering management. He holds a PhD in technological hazards, Universiti Kebangsaan Malaysia. His research interest is process safety, especially with respect to issues relating to industrial disaster risk reduction. He has authored and co-authored several books and academic articles on the safety and health's topics.

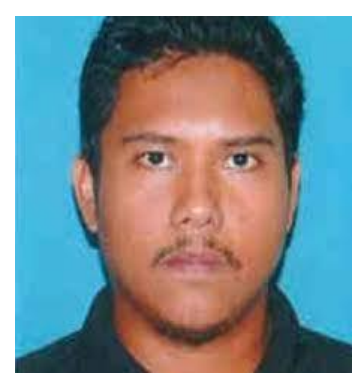

is a Senior Executive with an industrial firefighting and emergency service provider. He is an industrial practitioner in mind with academician spirit in heart. He obtained his degree in Electrical and Electronics Engineering from Universiti Teknologi PETRONAS and Master of Science in Industrial Safety Management from Universiti Kebangsaan Malaysia. He has more than 13 years working experience in industry particularly in oil and gas. He has delivered numerous HSE related training and being involved in consulting works. Since 2016, he also delivered emergency management lectures in a private university. His research interest includes fire protection system, emergency management and disaster risk reduction.

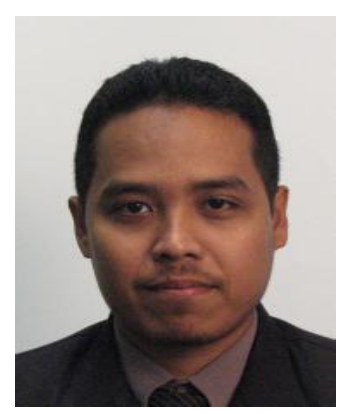

Mat Desa is currently a senior lecturer at the Faculty of Chemical and Process Engineering Technology, Universiti Malaysia Pahang (UMP). He received his PhD in the area of polymer engineering and MSc. in Process Plant Management from University Teknologi Malaysia and B. Eng. in Chemical Engineering from Universiti Kebangsaan Malaysia. He gives lectures on materials engineering, engineering economics and process management at bachelor and postgraduate degree level in UMP. His area of research interests includes polymer processing, thermal characterization, toughened polymers, nanocomposites polymers and risk management. 


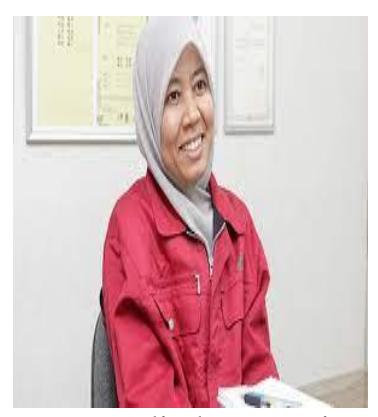

Noor Haslinda Hanapi received her Bachelor of Engineering in Mechanical from Gunma University, Japan in 2005 and completed her Master of Engineering in Manufacturing Systems from Universiti Kebangsaan Malaysia in 2013. Worked as an engineer in a Japanese manufacturing company for five years before joining ADTEC Jerantut as a lecturer in 2010. Currently, she is part of the TVET team, teaching the diploma level for welding and manufacturing engineering courses. Hold a professional certificate in non-destructive testing (NDT) and responsible for the NDT certification at the institute, also appointed as the internal auditor for JKKP after passing the SHO exam in 2013. 